\title{
O GÊNERO LITERATURA DE CORDEL TRABALHADO NO COTIDIANO ESCOLAR
}

\author{
GUIRALDELLI, Lisângela Aparecida ${ }^{1}$ \\ ZANELATO, Leandra Aparecida Silva ${ }^{1}$ \\ OLIVEIRA, Lívia Regina Rezende ${ }^{1}$ \\ FARIA, Luís Gabriel Silva de ${ }^{1}$ \\ COSTA, Maria Vilma Pontes da ${ }^{1}$ \\ NOGUEIRA, Thiago Afonso ${ }^{1}$
}

RESUMO: O trabalho faz parte do projeto PIBID, financiado pela CAPES, e aplicado na E.M.E.F. Jardim Guanabara-Ituverava/SP. Essa pesquisa busca trabalhar a leitura, interpretação e produção de textos, focando a coerência e a coesão textual no ensino de Língua Portuguesa, a fim de levar o aluno a ser capaz de identificar e produzir textos dos mais variados gêneros, considerando o contexto, a situação de comunicação, os interlocutores, o conhecimento de mundo e o conhecimento linguístico, o grau de formalidade e o uso descritivo dos elementos da língua. Baseando-se nos estudos e nas noções teóricas de gênero discursivo de alguns autores como Bakthin (1992), Bronckart (1999), Marcuschi (2003, 2008) e Alves Filho (2011), este estudo apresenta como atividade o trabalho com a literatura de cordel (dentro da esfera literária) no cotidiano escolar. No decorrer do projeto, foram trabalhados os conceitos de gêneros discursivos, o panorama histórico e os usos do cordel e elaborados materiais didáticos contendo atividades práticas e procedimentais para serem aplicadas junto à sala de aula. Alguns motes tratados pelos cordéis (bichos, malandragem, viagens fantásticas, humor, temática social etc.) foram apresentados aos jovens alunos pelos bolsistas para que a discussão e a leitura desses folhetos culminassem em produções textuais em formato de cordel.

Palavras-Chave: Gênero discursivo. Literatura de Cordel. Produção textual.

SUMMARY: This research is part of a larger project called PIBID, funded by CAPES, and is being implemented in E.M.E.F. Jardim Guanabara-Ituverava/SP. This work seeks to work reading, interpretation and text production, focusing cohesion and textual coherence in Portuguese teaching, in order to get the student to be able to identify and produce texts in several genders, considering context, communicative situation, speakers, world and linguistic knowledge, degrees of formality and the descriptive use of language elements. Based on studies and theoretical notions of discursive gender by some authors like Bakthin (1992), Bronckart (1999), Marcuschi (2003, 2008) e Alves Filho (2011), this study presents as activity the work with cordel (within literary sphere) in everyday school life. During the project, the scholarship students present the concept of discursive gender, the historical background and the uses of cordel and elaborate educational material containing practical and procedural activities to be implemented in the classroom. Some topics covered by cordel (animals, trickery, fantastic travels, humor, social issues etc.) were presented to young students by scholarship students and the classroom read, discuss and produce cordel by themselves.

Keywords: Discursive gender. Cordel. Textual Production.

\section{INTRODUÇÃO}

O trabalho faz parte do projeto denominado PIBID (Programa Institucional de Bolsa de Incentivo à Docência), financiado pela CAPES (Coordenação de Aperfeiçoamento de Pessoal de Nível Superior), aplicado na E.M.E.F. Jardim Guanabara-Ituverava/SP- em uma sala de $7^{\circ}$ ano do Ensino Fundamental II, com 35 alunos, no ano de 2015. Baseando-se nos estudos e nas noções teóricas de gênero discursivo de alguns autores como Bakthin (1992), Bronckart (1999), Marcuschi (2002, 2008) e Alves Filho (2011), este estudo, que é a continuidade de um trabalho iniciado em 2014,

\footnotetext{
${ }^{1}$ Fundação Educacional de Ituverava
} 
apresenta como atividade o trabalho com a literatura de cordel (dentro da esfera literária) no cotidiano escolar.

Sendo assim, como objetivos gerais, a pesquisa trabalha a leitura, a interpretação e a produção de textos, focando a coerência e a coesão textual no ensino de Língua Portuguesa, a fim de levar o aluno a ser capaz de identificar e produzir textos dos mais variados gêneros, considerando o contexto, a situação de comunicação, os interlocutores, o conhecimento de mundo e o linguístico, o grau de formalidade e o uso descritivo dos elementos da língua. Além disso, este trabalho procura refletir, dentro da esfera literária, sobre o gênero literatura de cordel e reconhecer sua função social, suas características e seu valor pedagógico para o trabalho em sala de aula no que se refere à linguagem, ao discurso e aos valores enunciados.

Como objetivos específicos, o estudo busca i) incentivar o interesse pela leitura e escrita da língua portuguesa; ii) fornecer informações necessárias para uma melhor compreensão do gênero cordel; iii) valorizar a criatividade dos alunos, estimulando-os através da produção de cordéis; iv) promover a aproximação com a cultura popular, principalmente a nordestina, através do conhecimento da literatura de cordel; v) introduzir a questão do uso da linguagem, da variação linguística, da sonoridade e rimas, e da linguagem como meio para construção de significado e conhecimento, pois a literatura de cordel possibilita ao aluno entender essa variação e o faz conhecer uma estrutura que segue características próprias e que se diferencia dos outros gêneros textuais.

Para alcançar os objetivos descritos, o percurso metodológico trilhado teve início com leituras e levantamento bibliográfico referentes às questões de gênero discursivo e literatura de cordel. Foram trabalhados os conceitos de gênero discursivo, o panorama histórico e os usos do cordel. Essas noções aliadas às atividades e aos materiais didáticos propostos e elaborados, contendo atividades práticas e procedimentais, foram aplicados em sala de aula. Alguns motes tratados pelos cordéis (bichos, esperteza e malandragem, viagens fantásticas, humor, temática social) foram apresentados aos jovens alunos do $7^{\circ}$ ano, pelos bolsistas, para que a discussão desses folhetos, seguida de leitura e produção textual (produção de cordel, versos em forma de cordel, cordel reescrito em forma de prosa, xilogravuras ilustrativas dos textos lidos ) retratasse diversos aspectos da sociedade e funcionasse como instrumento de reflexão, uma vez que o contato com uma variedade de gêneros pode levar os jovens a ter mais poder de participação na vida cotidiana (ALVES FILHO, 2011). Além disso, os alunos puderam observar que foi por meio da literatura de cordel que o nordeste brasileiro conseguiu propagar as manifestações populares, as lutas, os sonhos e os desejos de pessoas simples.

Num primeiro momento, o trabalho em sala priorizou leituras e discussões teóricas para que os conceitos de gênero e cordel, por exemplo, ficassem bem esclarecidos. Num segundo momento, os temas e atividades trabalhados converteram-se em produções dos alunos em forma de cordel.

\section{GÊNERO DISCURSIVO}

\subsection{Sobre o gênero discursivo}

De acordo com a literatura, desde a década de 90, investigar os gêneros textuais passou a ter grande importância para os estudiosos da língua. E de acordo com análises, esses pesquisadores levantaram a questão dos gêneros textuais, porque desejavam estabelecer uma classificação para os textos de acordo com as características que cada um possuía. Como se observa, os conceitos e noções dadas ao gênero discursivo são muitas e distintas e, segundo Bakhtin (1992, p. 262): 
[...] a riqueza e a diversidade dos gêneros do discurso são infinitas porque são inesgotáveis as possibilidades da multiforme atividade humana e porque em cada campo dessa atividade é integral o repertório de gêneros do discurso, que cresce e se diferencia à medida que se desenvolve e se complexifica um determinado campo.

Segundo a perspectiva de Bakhtin (1992), os gêneros do discurso são conceituados como tipos relativamente estáveis de enunciados que estão presentes nas esferas de troca, em cada esfera da atividade humana e da comunicação. Ou seja, nas palavras do autor, uma dada função, que pode ser científica, técnica, cotidiana e, oficial, e uma certa condição de comunicação discursiva, específica de cada campo ou esfera discursiva, geram determinados gêneros que possuem uma forma de composição, um plano composicional, e ainda um conteúdo temático e um estilo. Esses elementos juntos são usados como recursos necessários na constituição de um gênero textual discursivo.

Como observa Bronckart (1999), os gêneros são constituídos de ações de linguagem que exigem do agente produtor decisões para cuja execução ele necessita ter competência. Segundo o autor, a primeira das decisões a ser tomada é a escolha que deve ser feita a partir do rol de gêneros existentes, ou seja, ele elegerá o gênero que lhe parecer adequado ao contexto e à intenção comunicativa.

Para Koch e Elias (2006), os gêneros textuais são considerados práticas sócio-comunicativas e são constituídos de certo modo, com determinada função e de acordo com esferas de atuação humana. Dessa forma, para as autoras, a competência metagenérica leva o falante ao conhecimento sobre gêneros textuais, sua caracterização e sua função e permite que haja a adequação nas diversas manifestações e produções de eventos da vida social.

Segundo Marcuschi (2002), é impossível se comunicar verbalmente se não for por meio de algum gênero e por meio de algum texto, ou seja, por meio de um gênero textual. Essa visão segue uma noção de língua como atividade social, histórica e cognitiva, como observa o autor. Para ele, o gênero textual pode ser assim definido:

[...] como uma noção propositalmente vaga para referir os textos materializados que encontramos em nossa vida diária e que apresentam características sócio-comunicativas definidas por conteúdos, propriedades funcionais, estilo e composição característica. (MARCUSCHI, 2002, p. 22-23)

Corroborando a posição de Bakhtin, Marcuschi (2008) observa que os gêneros são formas textuais, escritas ou orais, consideradas estáveis, histórica e socialmente situadas; são entidades comunicativas em que há o predomínio de aspectos/critérios referentes a funções, propósitos, ações e conteúdos. Além disso, o autor considera os gêneros dinâmicos e de uma complexidade variável. Por isso, a ideia de explicar os gêneros textuais em termos de sua constituição e circulação socialmente falando. E por serem formas textuais encontradas na vida diária, Marcuschi dá como exemplo gêneros que podem ir de um telefone, passando por receitas, sermões, cartas, editais, romances e outros, a uma aula virtual, por exemplo.

Nas palavras de Alves Filho (2011), a concepção de gênero entende que são os próprios usuários que fazem uso diário dos gêneros os responsáveis pelo uso, pela mudança e manutenção e pela nomeação dos gêneros e, segundo o autor, "os gêneros são como os grupos sociais e os seres humanos que os usam: mutáveis, variáveis, dinâmicos, às vezes até mesmo contraditórios e irregulares.” (ALVES FILHO, 2011, p. 20).

Alves Filho (2011) observa que a dinamicidade do gênero discursivo é importante porque se percebe uma adequação do gênero às situações vivenciadas pelos seres humanos e, muitas vezes, essa dinamicidade surge em resposta às necessidades comunicativas de cada um. E se os gêneros são 
dinâmicos, isso faz com que eles possam, ao longo do tempo, mudar, variar conforme as necessidades e práticas comunicativas. $\mathrm{O}$ autor, porém, ressalta que essa mudança dos gêneros não acontecesse somente na forma, no conteúdo e no estilo, mas pode resultar de alterações no propósito comunicativo, ou seja, nas finalidades de um texto de determinado gênero, e nas funções sociais desses gêneros.

A questão sobre gêneros é uma questão muito ampla e há muito que se falar. Neste trabalho a proposta é salientar a importância e o trabalho de um gênero discurso, no caso o cordel, em sala de aula.

Tomando alguns conceitos e noções de gênero discursivo, segue uma apresentação sobre o gênero literatura de cordel, demonstrando sua estrutura composicional, sua temática e estilo e, na sequência, serão apresentados os relatos de experiência das atividades desenvolvidas em sala de aula.

\subsection{Esfera literária: gênero Literatura de Cordel}

De acordo com Benjamin (1994, apud EVARISTO, 2011, p. 119), a história do cordel pode ser associada à tradição medieval, em que a atividade de contar histórias em determinadas comunidades se fazia presente entre seus integrantes. Um certo narrador anônimo contava experiências e, com essa ação, transmitia ensinamento moral, um provérbio, uma sugestão prática, uma regra de vida.

De acordo com estudos, o nome Cordel teve origem em Portugal, onde os livretos eram expostos em barbantes, como roupas no varal. Segundo Marinho e Pinheiro (2012), esses livros eram produzidos com material barato e vendidos em feiras, praças e mercados. Em Portugal, os cordéis eram escritos e lidos por indivíduos pertencentes à classe média como, por exemplo, professores, advogados, médicos, padres, considerados letrados.

A literatura de cordel é um tipo de poesia popular, originalmente oral, e depois impressa em folhetos rústicos expostos para venda, pendurados em cordas ou em cordéis, o que deu origem ao nome. São textos escritos em forma rimada e alguns poemas são ilustrados com xilogravuras (gravuras talhadas em madeira cujas formas dos desenhos são simples e apresentam paisagens, personagens nordestinas; as xilogravuras acompanham o conteúdo do folheto e também são usadas nas capas). A estrutura do cordel pode ser composta por quadra (estrofe de quatro versos); sextilha (estrofe de seis versos); septilha (estrofe de sete versos e essa é a mais rara); oitava (estrofe de oito versos); quadrão (os três primeiros versos rimam entre si, o quarto com o oitavo e o quinto, o sexto e o sétimo também entre si); décima (estrofe de dez versos) e martelo (estrofes formadas por decassílabos (estes são muito comuns em desafios e versos heróicos). As estrofes mais comuns são as de dez, oito ou seis versos e os autores, ou cordelistas, como também são chamados, recitam esses versos de forma melodiosa e cadenciada, acompanhados, algumas vezes, de viola.

No Brasil, o cordel é considerado sinônimo de poesia popular feita em versos. "As histórias de batalhas, amores, sofrimentos, crimes, fatos políticos e sociais do país e do mundo, as famosas disputas entre cantadores, fazem parte de diversos tipos de texto em verso denominados literatura de cordel." (MARINHO; PINHEIRO, 2012, p.17). Assim, a temática tratada pelo cordel, de acordo com os autores, envolve a presença de animais, ou seja, o mundo dos bichos, fatos do cotidiano, episódios e personagens históricos, temática social, lendas e viagens fantásticas, temas religiosos, humor e esperteza e malandragem. As façanhas do cangaceiro Lampião e o suicídio do presidente Getúlio Vargas, por exemplo, são alguns dos assuntos de cordéis de maior tiragem. E é bastante comum os autores ou cordelistas criarem seus versos de maneira improvisada diante de um acontecimento ou uma pessoa que queiram homenagear. 
Como observa Evaristo (2011, p. 120), o cordel "constituiu-se em um gênero intermediário entre a oralidade e a escrita. Faz uma espécie de ponte de passagem entre uma cultura popular e outra, literária. Por isso, mantém algumas pistas da oralidade ao ser transposto para o texto escrito e impresso".

Trazida pelos nossos colonizadores, a literatura de cordel instalou-se primeiramente na Bahia, em Salvador, e dali espalhou-se para os outros estados nordestinos. No Brasil, a literatura de cordel é produção típica do Nordeste, principalmente nos estados de Pernambuco, Paraíba e Ceará. Os folhetos costumam ser vendidos em mercados e feiras pelos próprios autores. Em outros Estados, por conta da migração nordestina, como Rio de Janeiro, Minas Gerais e São Paulo, são encontrados em feiras de produtos nordestinos. Segundo Evaristo (2011), a literatura de cordel, nos dias de hoje, tem se aproximado de novos meios de elaboração e produção como, por exemplo, o computador. Mas para a autora, o interessante é que o cordel acompanha mudanças e inovações e mantém elementos tradicionais.

\section{RELATOS DE EXPERIÊNCIA}

Seguindo as orientações do Subprojeto de Letras que norteiam as ações na escola parceira, essa atividade apresentou como objetivo conciliar os dois processos (leitura e escrita), buscando nos alunos a apropriação da escrita ao refletir sobre a diferença entre a linguagem oral e a escrita e despertando neles a criatividade e a imaginação.

A atividade foi conduzida em parceria com a escola E.M.E.F. "Jardim Guanabara", considerando as metas sugeridas pelo subprojeto, pela coordenação do PIBID e pela equipe gestora da escola.

Acerca da metodologia aplicada, após a identificação das necessidades dos alunos, foi definido que a intervenção aconteceria no processo de leitura, interpretação e produção de textos, ressaltando a importância da construção da atividade em prosa para o cordel. Foram observadas aulas ministradas pela professora supervisora constatando-se a interação da classe com a regente. O filme "Jack o caçador de gigantes" foi exibido para os alunos para que, em seguida, relatassem a história em forma de prosa. Com o texto em mãos, a sala trabalhou a escrita para o cordel. Nessa atividade avaliou-se a produção de cordéis feita pelos alunos, a transcrição de diálogos, os versos para cordel, as rimas, a sonoridade entre outros, considerando as apresentações orais e escritas dos educandos durante o processo criativo.

Depois de aplicadas atividades a partir de filme, decidiu-se por trabalhar com contos de Erico Verissimo, pensando na possibilidade de que, por meio de outros gêneros discursivos, as crianças pudessem, com criatividade e imaginação, transformá-los em cordéis. Além disso, como observa Alves Filho (2011, p. 22), "aprender e dominar certos gêneros pode ser uma condição para compreender certas experiências e significados." Foram apresentados aos alunos seis contos:

- Os três porquinhos pobres

- Outra vez os três porquinhos

- As aventuras do avião vermelho

- O Urso com música na barriga

- A vida do elefante Basílio

- Rosa Maria e o castelo encantado

A sala foi dividida em grupos de cinco a seis alunos, falou-se de cada história, e foi feita a leitura dos contos por grupo. Houve discussão com os grupos para saber o que cada um achou dos contos apresentados e após a leitura os alunos fizeram a reescrita do texto em prosa no caderno do Subprojeto do PIBID. Após a reescrita os grupos desenvolveram os cordéis referentes aos seus contos. Em seguida os 
cordéis foram corrigidos e os alunos receberam papel sulfite colorido, lápis coloridos e cada grupo usou da criatividade para fazer desenhos ilustrativos para as capas dos cordéis. Ao trabalhar os contos de Erico Verissimo com os alunos pode-se refletir sobre o propósito comunicativo dos contos, ou seja, a condição do ser humano, e ao transformar esses contos em cordéis, pode-se trabalhar a temática social, que é um dos motes tratados pela literatura de cordel.

Como afirma Devitt (2009, apud ALVES FILHO, 2011), os gêneros são ótimos objetos de ensinoaprendizagem se forem vistos com um significado cultural e social.

Após finalizar a atividade dos contos de Érico Veríssimo, foi dada sequência aos trabalhos e decidiu-se por trabalhar com as fábulas, cujo propósito comunicativo é o de orientar o comportamento de pessoas, além de estabelecer relação com a variedade de temas apresentados pela literatura de cordel, para mostrar aos alunos como essa multiplicidade de gêneros existentes pode ser trabalhada e transformada em cordel, e como o trabalho com a literatura de cordel favorece o diálogo e o envolvimento com a cultura popular.

Antes de iniciar a atividade, a sala foi dividida em grupos; os alunos fizeram a leitura das fábulas, prática essa que proporcionou a eles observar também as características desse gênero. Em seguida os alunos fizeram cópia das fábulas para o caderno do PIBID. As fábulas trabalhadas foram:

- A Lebre e a Tartaruga

- O Cão e a Carne

- A Cigarra e a Formiga

- O Urso e os dois Viajantes

- O Burro, a Raposa e o Leão.

A atividade consistiu em cada grupo selecionar duas fábulas para transformar as histórias em cordel, usando a criatividade e seguindo a estrutura, as rimas, a sonoridade e o estilo desse gênero.

Com os cordéis prontos no caderno, foi feita a correção e, em seguida, a sala recebeu folhas coloridas e lápis coloridos para feitura de um livreto de Cordel.

Essa atividade entrelaçou dois gêneros diferentes e proporcionou aos alunos maior conhecimento sobre diferentes gêneros textuais. Segundo Alves Filho (2011), o contato com uma variedade de gêneros pode levar os jovens a terem mais poder de participação na vida cotidiana.

Com o intuito de trabalhar, dentro da esfera literária, o gênero cordel e fazer com que os alunos reconheçam sua função social, suas características e seu valor pedagógico para o trabalho em sala de aula, a escola se torna um importante espaço de divulgação dessa literatura popular, que apresenta uma variedade de temas, como já foi dito, que levam os alunos a fantasiar, imaginar, refletir e discutir uma série de questões humanas essenciais. E como observam Marinho e Pinheiro (2012, p. 133), "o mais importante de tudo isto é que a literatura de cordel seja percebida como uma produção cultural de grande valor e que precisa ser conhecida, preservada e cada vez mais integrada à experiência de vida de nossas gerações."

\section{REFERÊNCIAS}

ALVES FILHO, F. Gêneros textuais jornalísticos: notícias e cartas de leitor no ensino fundamental. São Paulo: Cortez, 2011.

BAKHTIN, M. Estética da criação verbal. São Paulo: Martins Fontes, 1992. 
BRONCKART, J. P. Atividade de linguagem, textos e discursos: por um interacionismo sócio discursivo. São Paulo: Educ, 1999.

EVARISTO, M. C. O cordel em sala de aula. In: BRANDÃO, H. N. Gêneros do discurso na escola: mito, conto, cordel, discurso político, divulgação científica. 5.ed. São Paulo: Cortez, 2011. p. 119-186. (Coleção Aprender e ensinar com textos. v. 5, Coordenação geral: Lígia Chiapini)

KOCH, I. V. G.; ELIAS, V. M. Ler e compreender: os sentidos do texto. 2.ed. São Paulo: Contexto, 2006.

MARCUSCHI, L. A. Gêneros Textuais: definição e funcionalidade. In: DIONÍSIO, A. P.; MACHADO, A. R.; BEZERRA, M. A. (Orgs.) Gêneros textuais e ensino. 2. ed. Rio de Janeiro: Lucerna, 2002.

MARCUSCHI, L. A. Produção textual, análise de gêneros e compreensão. São Paulo: Parábola, 2008.

MARINHO, A. C.; PINHEIRO, H. O cordel no cotidiano escolar. São Paulo: Cortez, 2012. (Coleção Trabalhando com ... na escola) 
